\title{
Um Olho no Peixe e Outro no Gato: Como as Fintechs Disputam Espaço com os Bancos em Época de Juros Baixos
}

\section{An Eye on the Fish and Another on the Cat: How the Fintechs Dispute Space with the Banks in Times of Low Interest}

\author{
Raul Beal Partyka \\ Jeferson Lana \\ Marina Amado Bahia Gama
}

Este caso de ensino contextualiza a evolução e transformação do Sistema Financeiro brasileiro, com destaque para o crescimento das fintechs (empresas financeiras de base tecnológica) e ruptura do momento de "sossego" dos grandes bancos. Com o surgimento das fintechs, o market share dos grandes bancos passa a ser ameaçado. Com isso, este caso tem por objetivo discutir as estratégias de mercado concorrenciais dos bancos e das fintechs frente aos cenários futuros possíveis, sobretudo, analisar as estratégias das fintechs com enfoque nas atividades políticas corporativas sob forma de influenciar o governo, a regulação e o Sistema Financeiro Nacional para obter acesso ao mercado. O caso ainda permite avaliar a integração das estratégias de mercado e de não mercado, atuando frente a um interesse em comum, entre as fintechs e os grandes bancos. Trata-se de um caso real dentro do contexto brasileiro. Pode ser utilizado em cursos de graduação e de pós-graduação em Administração, Ciências Contábeis, Economia e Gestão. Ainda pode ser utilizado em cursos complementares, de curta duração ou educação executiva, em temáticas tais como Relações Governamentais e Relações Institucionais e Estratégia de Não Mercado.

Palavras-chave: Fintechs. Bancos. Atividade Política Corporativa. Estratégia.

This teaching case contextualizes the evolution and transformation of the Brazilian Financial System, with emphasis on the growth of the fintechs (technology-based financial companies) and the rupture of the moment of "quiet" of the big banks. With the emergence of Fintechs, the market share of major banks is threatened. The purpose of this case is to discuss the com-
Recebido em: 27/01/2019 Aprovado em: 08/06/2019

Raul Beal Partyka iD
raul@edu.univali.br
Mestre em Administração pela
Universidade do Vale do Itajaí
Master in Business Administration -
University of Vale do Itajaí
Universidade do Vale do Itajaí
Biguaçu/SC - Brasil
Jeferson Lana iD
jlana@univali.br
Doutor em Administração de Empresas
pela FGV/EAESP
PhD in Business Administration - FGV/
EAESP
Universidade do Vale do Itajaí
Biguaçu/SC - Brasil
Marina Amado Bahia Gama ID
abgama@gmail.com
Doutora em Administração de Empresas
pela FGV/EAESP
PhD in Business Administration - FGV/
EAESP
Fundação Getúlio Vargas - Escola de
Administração de Empresas de São
Paulo
São Paulo/SP - Brasil


petitive market strategies of banks and Fintechs in the face of possible future scenarios, in particular, to analyze fintech strategies with a focus on corporate political activities in the form of influencing government, regulation and the System National Bank to gain access to the market. The case also allows us to evaluate the integration of market and non-market strategies, acting in the face of common interest, between fintechs and large banks. This is a real case within the Brazilian context. It can be used in undergraduate and postgraduate courses in Administration, Accounting, Economics, and Management. It can also be used in complementary courses, short courses or executive education, in subjects such as Government Relations and Institutional Relations and Nonmarket Strategy.

Keywords: Fintechs. Banks. Corporate Political Activity. Strategy.

\section{Introdução}

Desde o final dos anos 1990 e início dos anos 2000, o Brasil tem produzido iniciativas relevantes de inclusão financeira. São exemplos disso os correspondentes bancários, o internet banking e, mais recentemente, o mobile banking. Os avanços tecnológicos promovem o acesso a soluções e ferramentas colocadas à disposição do consumidor brasileiro, devido ao enorme investimento dos bancos nesse sentido, ao longo dos últimos anos.

Assim, o Brasil e o mundo estão experimentando uma onda de crescimento da tecnologia financeira, que provavelmente irá absorver uma fatia de mercado dos bancos tradicionais. Dentre as principais novidades tecnológicas estão as fintechs. Trata-se de jovens empresas financeiras, também chamadas de startups do setor financeiro, diferenciadas pelas suas inovações e tecnologias aplicadas aos serviços. $O$ termo vem do inglês, que une a palavra financial (financeiro) com a abreviação de technology (tecnologia).

Em 2015 havia apenas algumas dezenas de fintechs instaladas no país. Em abril de 2016, o número chegou a 130 (NERY, 2016). Um relatório do Goldman Sachs, empresa líder em gestão de investimento, títulos e investimentos globais com sede em Nova lorque, estima que as mais de 200 empresas de tecnologia financeira atuando atualmente no Brasil devem gerar uma receita potencial de cerca de 24 bilhões de dólares nos próximos dez anos (SREEHARSHA, 2017). 
Dessa forma, pode-se observar que há mudanças ocorrendo. Ainda que a economia do Brasil esteja lutando para sair da recessão e a incerteza política tenha crescido antes das eleições de outubro de 2018, startups brasileiras levantaram quantias recordes de fundos (LEAHY, 2018) nesse ano. Assim, essas mudanças tecnológicas financeiras vêm acontecendo em um período de estagnação econômica e elevada incerteza política no Brasil. De um lado, há um mercado consumidor cansado das maiores taxas de juros do mundo. De outro, um governo buscando formas de incentivar o consumo e a retomada do crescimento. Entre esses dois extremos, estão os grandes bancos tradicionais e as fintechs, que agora competem entre si pelo mercado.

O Governo, especialmente por meio de suas instituições, órgãos e autarquias do Sistema Financeiro Nacional (SFN), precisa urgentemente estimular a economia e promover a recuperação econômica, diante da recessão iniciada em 2015. Os bancos, concentrados em cinco gigantes, não conseguem fomentar por si só o consumo da forma que o governo necessita. Desses cinco gigantes, "quatro instituições respondem por $80 \%$ das transações bancárias" (ARROYO, 2018). Em contraste, nos Estados Unidos, os cinco principais bancos detêm apenas cerca de $20 \%$ de todas as agências distribuídas pelo país. $\mathrm{Na}$ Índia, esse número é ligeiramente superior a $30 \%$, e na Turquia, é de pouco menos de $30 \%$. Os mercados financeiros do México e da Rússia também são menos concentrados que o do Brasil (SREEHARSHA, 2017).

llan Goldfajn, presidente do Banco Central do Brasil (BC) no período de junho de 2016 a fevereiro de 2019, enfatiza que: "Em vez de discutirmos se há ou não concentração, temos de discutir se há ou não competição no sistema. Mais competição ajuda? Se sim, então, vamos em frente, estimular competição, para podermos reduzir as taxas bancárias de forma mais acelerada". Para isso, o ex-presidente do BC baixou a taxa Selic para o menor patamar da história. Mas o crédito continua caro, e um dos motivos principais para tanto continua sendo o spread. Goldfajn mudou regulações, estimulou as fintechs e tirou os bancos da zona de conforto. É exemplo disso o cadastro positivo. "Deixamos isso muito claro: se o cliente quiser usar os serviços de uma fintech, o banco não pode dificultar isso" (GRADILONE, 2018a).

As startups brasileiras ainda são consideradas "peixe pequeno", se comparadas aos seus concorrentes estabelecidos. Além disso, os bancos tradicionais brasileiros também são conhecidos por sua sofisticada tecnologia financeira (LEAHY, 
2018). No entanto, ainda que os esforços para o aumento da competitividade financeira brasileira estejam sendo implantados com avanços significantes, as fintechs e demais concorrentes continuam a sentir as dificuldades de um ambiente regulatório complexo e limitado.

Portanto, diante desse contexto, a pergunta que se faz é sobre quais são as estratégias de mercado e não mercado que os bancos e as fintechs utilizam para influenciar o governo e o sistema financeiro nacional frente ao cenário de juros baixos. Sendo assim, o dilema deste estudo de caso reside nos esforços que as fintechs têm empreendido para crescer no mercado e para pressionar o SFN a buscar novas regras, estímulos regulatórios, que permitam sua atuação nos mais diversos segmentos financeiros do país. Mais especificamente, este estudo de caso enfoca as estratégias de mercado e não mercado que têm sido utilizadas pelas fintechs e se estas têm cumprido o papel desejado.

\section{Redução das taxas de juros: dinheiro disponível para a} população

Por que incentivar fintechs? Por que o governo não incentiva o consumo por si, imprimindo mais dinheiro? Bem, um governo que emite dinheiro, por definição, não pode quebrar da mesma forma como uma empresa, que depende de receitas. Sim, governos podem imprimir dinheiro e gastar. Mas isso pode, em casos específicos, causar inflação (SICSÚ, 2017). A impressão de dinheiro não acompanha um aumento na produção de bens e serviços: com mais dinheiro no bolso, as pessoas compram demais, a oferta de produtos diminui e estes encarecem.

Não se trata de uma suposição, a história comprova esses fatos. Quando Juscelino Kubitschek presidiu o país, entre 1956 e 1961, foi necessário imprimir papel moeda em maiores quantidades, para pagar as dívidas criadas pelo seu projeto de expansão. O processo de inflação que se seguiu a essa medida foi tão grande que somente pôde ser contido décadas depois, com a implantação do Plano Real, em 1994. Para se ter noção, em 1993 a inflação anual chegou a 2.477\%. Dessa forma, imprimir dinheiro não é uma solução para a miséria: no final, os pobres continuariam pobres, mas com notas desvalorizadas no bolso (SANT'ANA, 2017). 
Da mesma forma, o ex-presidente do BC respondeu a esta mesma questão em abril de 2018, em uma de suas palestras, afirmando que imprimir dinheiro para pagar dívidas já foi algo tentado muitas vezes, mas que, no final, resultou apenas em geração de mais inflação: "Se há a impressão de mais dinheiro, havendo a mesma quantidade de bens, haveria mais inflação". Ou seja, o excesso de dinheiro em circulação elevaria os preços das mercadorias e minaria o equilíbrio da economia (RIZÉRIO, 2018).

Uma forma alternativa de repassar dinheiro à população seria diminuir as taxas de juros. Isso faria muitas famílias optarem por manter seu dinheiro em circulação em vez de investido. Nos Estados Unidos (EUA), por exemplo, após a crise de 2008, o Federal Reserve Bank (FED - o Banco Central Americano) baixou sua taxa básica de juros a zero.

Nesse sentido, o que está acontecendo no Brasil? Ainda há recessão, desemprego, empresas fechando, consumo baixo, preços estáveis ou caindo. Por outro lado, o Banco Central está reduzindo os juros, e os consumidores estão menos preocupados com a inflação e mais preocupados em ver a economia crescer.

Os juros mais baixos ajudam nisso. Conforme aponta a Figura 1, juros menores aliviam também a vida das empresas, que podem inclusive começar a investir mais, o que ajuda o país a sair da crise (ANBIMA, 2017).

Figura 1 Projeção da economia no Brasil.

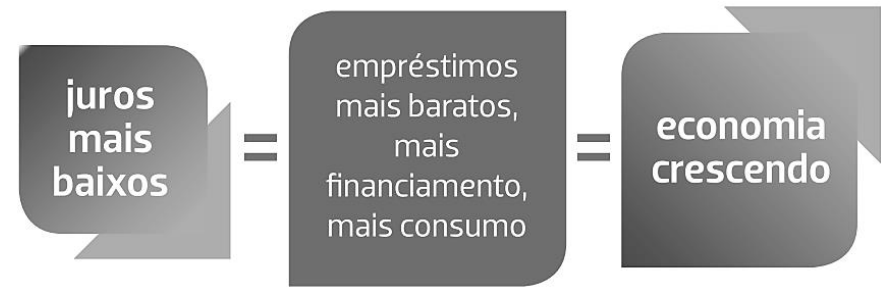

Fonte: Anbima (2017).

Sem esquecer-se das grandes instituições, Goldfajn relatou que "a Selic é apenas um dos componentes da taxa bancária. O resto é falta de garantias [...]. Vamos ter de lidar com tudo isso ao longo do tempo" (GRADILONE, 2018b). Nesse sentido, houve mudanças também no tratamento dos empréstimos rotativos dos 
cartões de crédito, e a Federação Brasileira de Bancos (Febraban) já planejou e encaminhou a alteração dos juros do cheque especial. Essas mudanças alteram a forma tradicional de funcionamento dos bancos, e estes se privam de uma parte dos ganhos. Porém, os grandes bancos não estão conseguindo, ou não estão querendo, ceder e oferecer juros mais baratos.

\section{AS FINTECHS NO BRASIL}

As fintechs instaladas no Brasil têm representado uma crescente esperança para a redução do spread bancário e, consequentemente, das taxas de juros. "O crescimento das fintechs no Brasil está diretamente relacionado a uma regulação atenta às mudanças do segmento, preocupada em fomentar novos modelos de negócio" (PERRIN, 2018).

Em 2016, o BC e a Comissão de Valores Mobiliários (CVM) criaram núcleos internos para monitorar fintechs (BRASIL, 2016), enquanto se movimentavam para regular atividades que vêm ganhando maior visibilidade. De forma geral, os empreendedores elogiam a atuação dos reguladores, que têm se mostrado flexíveis para evitar o cumprimento de regras anacrônicas (ALVES, 2017a). Em fevereiro de 2017, já estavam atuando cerca de 250 dessas startups. Até novembro de 2017, o número pulou para 332 fintechs em atividade no Brasil. Em agosto de 2018, mais de 400 (ver Anexo A) já estavam mapeadas (FINTECHLAB, 2018a).

Inicialmente, as fintechs no Brasil receberam apoio de instituições de fomento para seus planos de crescimento. Órgãos como a Corporação Financeira Internacional (IFC, do inglês International Finance Corporation), membro do grupo do Banco Mundial, e a Financiadora de Inovação e Pesquisa (Finep), ligada ao Ministério de Ciência e Tecnologia, têm apoiado essas plataformas por meio de empréstimos ou investimentos diretos. Exemplo disso é a fintech GuiaBolso, plataforma de finanças pessoais que, em maio de 2016, recebeu 60 milhões de reais de investidores capitaneados pela IFC (FINTECHS CRESCEM..., 2017). Sergio Furio, criador da fintech Creditas, confirma o modelo de negócios da empresa como baseado na concessão de crédito usando a propriedade dos clientes como garantia. Com isso, a Creditas consegue cobrar juros de 1,15\% ao mês por crédito de veículos e 1,49\% por crédito com garantia de imóvel, muito abaixo, portanto, dos $6 \%$ cobrados pelos bancos (ALVES, 2017b). 
A Nubank, uma das fintechs mais populares, nasceu na Rua Califórnia, no bairro paulistano do Brooklyn, em maio de 2013, e permaneceu naquele endereço até janeiro de 2015. Hoje ela está sediada no bairro paulistano de Pinheiros e tem mais de 500 funcionários. O colombiano David Vélez, fundador da fintech, é formado em engenharia pela universidade de Stanford. Lá trabalhava para o fundo de venture Capital Sequoia, o mesmo que deu o primeiro milhão de dólares para Steve Jobs alavancar a Apple.

Vélez desembarcou no Brasil em 2011 para encontrar oportunidades de investimentos. Não encontrou nada interessante. Esbarrou na burocracia quando precisou abrir uma conta bancária. Daí surgiu a ideia, e desde então recebeu aportes até mesmo do seu antigo empregador, o Sequoia Capital. "Havia uma grande crença convencional, que eu via em 2012 e 2013, de que não dava para competir com os grandes bancos" (SAMBRANA, 2017).

Primeiramente, pensou: "Não temos o capital e nem a infraestrutura que eles têm, mas temos tecnologia, uma cultura muito forte, somos rápidos e pensamos no cliente". No dia 24 de outubro de 2017, Vélez anunciou, em um auditório lotado por clientes, parceiros e geekies, a criação da NuConta: uma conta bancária na qual o dinheiro depositado passava a render automaticamente a uma taxa indexada ao CDI. Formaram-se filas na rua.

Até então, a atuação da fintech era restrita ao oferecimento de cartão de crédito sem custo de manutenção. Para quem pensa que a disputa é apenas por tirar clientes dos maiores bancos, se engana. A ideia é oferecer o serviço para $100 \%$ da população, sobretudo aos 60 milhões de brasileiros que não têm conta bancária (SAMBRANA, 2017). Banco do Brasil e Bradesco, por exemplo, criaram, em 2016, a Digio, plataforma tecnológica de cartões de crédito, inspirando-se no surgimento do Nubank (ALVES, 2017a).

Empresas de capital de risco já investiram, desde 2013 até abril de 2018, 179 milhões de dólares no Nubank, fintech avaliada em 500 milhões de dólares no início de 2016 (ALVES, 2018). No entanto, Vélez estava enfrentando, com poucas estratégias disponíveis, adversários mais poderosos, os cinco gigantes: Itaú Unibanco, Bradesco, Santander, Banco do Brasil e Caixa Econômica. Estes estavam criando dificuldades para o Nubank na contratação de serviços bancários necessários à sua atividade, como débito automático, extrato intraday e serviços de banco liquidante, 
além da restrição a informações essenciais, como identificação de remetente de recursos (ARROYO, 2018).

Além disso, todos os clientes da empresa de Vélez pagavam suas faturas via boleto, o que elevava os custos e o risco de inadimplência. Os bancos enviaram ao CADE a proposta de cobrar tarifas entre 6 e 11 reais por boleto autenticado, enquanto dados do Banco Central (BC) indicavam que a tarifa média era de 3,64 reais. Dessa forma, Vélez precisava de mais recursos estratégicos para derrubar os gigantes. Então, após uma petição enviada pelo Nubank ao Conselho Administrativo de Defesa Econômica (CADE), novas mudanças na regulação foram aprovadas em meados de março de 2018, tornando a disputa menos desigual.

Assim, em 28 de março de 2018, as fintechs ganharam um aliado: o governo federal, que, por meio do Conselho Monetário Nacional (CMN), aprovou a Resolução N 4.649 (BRASIL, 2018a). Esta resolução proíbe aos bancos criarem problemas aos débitos automáticos e às transferências de dinheiro, dentre outros exemplos. O principal apelo das startups é que possam, por meio da tecnologia, promover a redução ou inclusive dispensar a tarifa cobrada aos clientes. Tais regulamentações devem ser um alívio para as fintechs (ARROYO, 2018).

Um fato ocorrido em 2017 também beneficiou o Nubank, quando este contratou o ex-presidente do Banco Central, Gustavo Franco. Também co-fundador da gestora Rio Bravo, onde permanece trabalhando, o agora consultor estratégico integrou o time da fintech. A intenção era que o economista apoiasse a jovem startup em estratégias de mercado, não mercado e questões macroeconômicas (ZOGBI, 2017).

Em janeiro de 2018, o presidente Michel Temer autorizou o Nubank a ser uma financeira, dando mais autonomia para a fintech, conhecida pelos cartões de crédito roxos. Na prática, a decisão significou que a startup não mais precisará de parcerias com bancos no país para montar sua estrutura de captação de recursos e oferta de crédito. Isto porque, apesar de ser uma empresa brasileira, o Nubank é controlado por uma holding sediada nas Ilhas Cayman e, nessa condição, a aprovação seria necessária. Segundo a legislação brasileira, uma instituição de capital estrangeiro depende de um decreto presidencial para se tornar uma financeira, processo que pode levar anos.

A partir de 2018, então, o Nubank pôde constituir uma vertente de negócios específica, a Nu Financeira (ALVES, 2018), e afirma ser a maior fintech de clientes 
fora da Ásia. As contas são abertas on-line e não há taxas - uma revolução para o setor bancário brasileiro, montado em burocracia. "Isso explica por que o Nubank conseguiu crescer mais rápido do que qualquer outro banco digital nos EUA e na Europa, embora a macroeconomia tenha sido muito pior", afirma Vélez (LEAHY, 2018).

No mesmo sentido, foi criado o Banco Original, primeiro banco $100 \%$ digital do Brasil, pelo ex-presidente do Banco Central e também ex-ministro da Fazenda, Henrique Meirelles. O grupo J\&F é proprietário desta já grande fintech, que teve Meirelles como presidente do Conselho do grupo, além de ter sido CEO do Bank of Boston nos anos 1990. Com frequência, seu nome aparece no cenário político (FRIEDLANDER, 2016).

As fintechs são submetidas a três órgãos reguladores no Brasil: a Superintendência de Seguros Privados (Susep), a Comissão de Valores Mobiliários (CVM) e o Banco Central (BC) (TRINDADE, 2017). Como parte da mobilização das fintechs, essas startups financeiras se organizaram para melhor se articularem junto aos órgãos reguladores. Foram formadas a Associação Brasileira de Fintechs (ABFintechs), a Associação Brasileira de Crédito Digital (ABCD), e ainda a Associação Brasileira de Equity Crowdfunding, estabelecida às vésperas da regulamentação do financiamento coletivo pela Comissão de Valores Mobiliários (CVM), em 2016 (NERY, 2016).

Além disso, na audiência de 26 de abril de 2018, na Comissão de Assuntos Econômicos (CAE) do Senado, estiveram presentes o diretor de relações institucionais do Nubank, Bruno Nagrani, e o professor da PUC-Rio, Vinícius Carrasco, executivo da fintech Stone, representando as fintechs brasileiras em defesa da aprovação do Cadastro Positivo. Este tem como objetivo central debater os altos níveis de spread praticados pelos bancos nacionais. Isto é, as instituições menores não têm nem de perto o mesmo nível de acesso às informações que os grandes bancos têm. Para o diretor do Nubank: "Se não tenho essa informação sobre o risco de cada cliente, vou assumir que os juros serão mais altos". Sendo assim, com o Cadastro Positivo, as informações sobre o crédito dado aos consumidores bancários poderão ser compartilhadas, e assim os competidores de qualquer nível poderão conceder crédito com ofertas mais agressivas (FINTECHLAB, 2018b).

Outra regulamentação favorável às fintechs, e também às partes interessadas, foi o Decreto No 9.283, de 7 de fevereiro de 2018 (BRASIL, 2018b), que regulamentou a política de incentivos à Ciência e Tecnologia. A principal liberação é a 
possibilidade de as universidades públicas, os centros de pesquisa, as agências de fomento, as empresas públicas e as sociedades de economia mista poderem participar como sócias de startups, tanto de forma direta como por meio de fundos de investimentos (FINTECHLAB, 2018c). O decreto ainda dá outras providências e dispensa certas exigências. Com isto, melhoraram as condições para avançar no termo ciência de excelência, por meio de uma legislação que permite ganho às duas partes. Com a regulamentação, a ciência levada à prática chega na ponta, às empresas, ao mercado.

Entretanto, as fintechs não promovem apenas ações diretas para lidar com a concorrência e exigir maior regulamentação. Elas procuram se antecipar ao mercado e dar sequência ao desenvolvimento de qualquer inovação que possa despontar. Nesse sentido, o banco digital Inter entrou com o pedido de oferta pública inicial de ações, em fevereiro de 2018. O Inter e seus acionistas poderão levantar até 815,96 milhões de reais com a Oferta Pública Inicial (IPO, do inglês Initial Public Offering). Em dezembro de 2017, o banco contava com 380 mil clientes e 3,5 bilhões de reais em ativos (MANDL, 2018). E o pleito se concretizou. O Banco Inter foi a primeira fintech brasileira a abrir capital na B3.

Também a ContaAzul, plataforma de gestão para empresas de pequeno porte, que contabilizou em 2017, 23 mil clientes, tem como estratégia dobrar o número de clientes usando escritórios de contabilidade parceiros da fintech como canais de venda. Ainda se pode citar a Thinkseg, fintech que vende seguros através de sua plataforma digital e possui cerca de 80 mil clientes ativos e 2 milhões de clientes cadastrados (FINTECHS CAMINHAM..., 2018).

Segundo Rodrigo Soeiro, presidente da Associação Brasileira de Fintechs, estas empresas estão no processo de consolidação, que já acontece internacionalmente e acontecerá também por aqui como uma tendência (FINTECHS CAMINHAM..., 2018). Para Sérgio Furio, presidente da Creditas, o Brasil possui um modelo de empréstimo com garantia que está à frente de mercados desenvolvidos, como o americano. Já na visão de Fábio Neufeld, presidente da Kavod Lending, uma fintech que atua com empréstimos entre pessoas, o Brasil não demorou muito mais tempo do que EUA e México para regular essas startups do setor financeiro. Neufeld considera que a legislação criada aqui é melhor, pois há maior flexibilidade (PERRIN, 2018). 
Na mesma tendência, o próprio Banco Nacional de Desenvolvimento Social (BNDES) criou um banco digital. Trata-se da fintech BNDES, com a finalidade de criar uma plataforma para fazer o fornecedor, que seja membro da Associação Brasileira da Indústria de Máquinas e Equipamentos (Abimaq), vender direto ao seu cliente. O objetivo é reduzir drasticamente o spread final. As estimativas com essa nova fintech é que as taxas anuais sejam inferiores a $12 \%$, dependendo do risco do cliente. O presidente da Instituição, Paulo Rabello de Castro, enfatiza que este é um dos segmentos aos quais o BNDES ainda não consegue chegar: pequenas, micro e médias empresas (RABELLO:..., 2018).

O BNDES tem como projeto, também por meio da contratação de um gestor de um fundo, emprestar dinheiro para startups. Chamado de Fundo de Coinvestimento Anjo, ele terá um patrimônio estimado em $\mathrm{R} \$ 100$ milhões. O próprio banco lançou uma iniciativa em 2007, chamada Fundo Criatec, que investe em empresas de tecnologia em estágio inicial. Entretanto, com recursos do BNDES e do BNB, este último investiu em apenas 36 startups (BNDES, 2017; PAMPLONA, 2017).

Somado a isso, o BNDES pretende diversificar sua rede de repassadores para garantir que pequenas e médias empresas tenham acesso aos financiamentos. Essa motivação vem em meio à resistência dos grandes bancos em oferecer crédito a micro, pequenas e médias empresas. Hoje, um dos principais focos do BNDES é em que micro, pequenas e médias empresas tenham acesso aos financiamentos. Especificamente, espera-se que as fintechs possam oferecer linhas ainda mais especializadas para determinados segmentos, como tecnologia ou saúde ('FINTECHS' PODEM..., 2017). Tudo isso para tornar o crédito mais abundante e barato e tirar milhões de brasileiros, tanto indivíduos quanto empresas, da atribulação dos juros altos pagos pelos empréstimos (GRADILONE, 2018b).

A fintech Toro trabalha no mesmo sentido, mas com outro canal. Ela lançou sua corretora em julho de 2018. O processo de aprovação da corretora pelos órgãos responsáveis iniciou em 2016 e no início de 2018 a Toro obteve as autorizações do Banco Central e órgãos reguladores. O foco da corretora será o investidor pessoa física, com oferta de produtos e serviços tanto de renda fixa quanto de renda variável (LAIER, 2018). Ela tornou-se uma das únicas empresas independentes do país - não ligadas a um banco - a abrir uma corretora nos últimos 20 anos e a primeira fintech da história a fazer esse movimento (RODRIGUES, 2018). 
Por fim, falando ainda de gigantes, o presidente do Santander no Brasil, Sérgio Rial, entende que a colaboração com as fintechs é a maneira de sobreviver a essas mudanças, mas o empreendedorismo não deve vir somente de fora. Para ele, os bancos não são apenas uma forma burocrática de existência. Rial minimiza o potencial conflito existente entre esses dois atores abordados neste estudo. Mais do que isso, ele considera uma proveitosa parceria já presente nesta interação: "Acho que temos que pensar na necessidade de se criar ecossistemas. Dentro do Santander, temos várias empresas que não são nossas, e em algumas questões a parceria com elas é fundamental" (MIOZZO, 2017).

Dessa forma, os grandes bancos estão investindo pesado em tecnologia e se movem rapidamente para superar a lacuna tecnológica que os separa das fintechs. Em cerca de três ou quatro anos, já terão condições de enfrentar as startups do setor de igual para igual em velocidade e inovação (FINTECHS CAMINHAM..., 2018).

\section{AS MUDANÇAS EM SÉRIE}

Colocado este cenário, observa-se que, em 2018, o então presidente do BC mostrou disposição de incentivar a concorrência: "Estamos fazendo quase todos os nossos regulamentos e normas baseados nisso e as fintechs também podem ser um novo vetor de competição nesse processo", declarou para a redação da Fintechlab (2018d). Goldfajn prometeu a regulamentação das fintechs de crédito: "Vamos deixar claro o que elas podem ou não fazer", afirmou, com a garantia de que os bancos não poderão, em qualquer hipótese, dificultar a vida do cliente que resolver servir-se de uma delas. As fintechs estavam no topo da agenda de Goldfajn, e não por seu tamanho, "mas sim pelo fator inovação, de mudança de cultura, de criar novos mecanismos que gerem disrupção". Goldfajn vê essas realizações com serenidade. "O atual governo veio com uma proposta de reformas, e aproveitamos essa janela de oportunidade", afirmou ele em 2018 (GRANDILONE, 2018b).

Uma das mudanças instituídas pelo BC foi a autorização dada às fintechs para receberem crédito de contas-salário. O Conselho Monetário Nacional (CMN) anunciou, em fevereiro de 2018, uma nova regra que entrou em vigor a partir em $1^{\circ}$ de julho do mesmo ano: os trabalhadores poderão transferir automaticamente o salário, sem pagar tarifas, para contas de pagamento não operadas por bancos, o que inclui contas digitais (FINTECHLAB, 2018e). O CMN é responsável por formular a 
política da moeda e do crédito. Seu objetivo institucional é assegurar a estabilidade da moeda e promover o desenvolvimento econômico e social do país.

Em 21 de março de 2018 também foi publicada a Lei $N^{\circ} 13.636$, que autoriza as fintechs a operar ou participar do Programa Nacional de Microcrédito Produtivo Orientado (PNMPO), com o objetivo de apoiar e financiar atividades produtivas de empreendedores, na distribuição de microcrédito (BRASIL, 2018c).

A maior conquista das fintechs pode ter vindo no dia 26 de abril de 2018. Até então, essas empresas de tecnologia do setor financeiro atuavam como correspondentes bancários na oferta de crédito, porém, nessa data, o CMN aprovou resoluções que permitem a essas empresas concederem crédito sem a necessidade da intermediação de um banco, podendo atuar em duas frentes: na forma de sociedades de empréstimos entre pessoas e como sociedades de crédito direto. Essas resoluções também permitem que as empresas desse setor sejam controladas por fundos de investimentos brasileiros ou estrangeiros (PRADO; CARNEIRO, 2018).

Somado a essas mudanças, o BC reduziu o valor dos depósitos compulsórios à vista, de $40 \%$ para $25 \%$, e o das cadernetas de poupança, de $24,5 \%$ para $20 \%$, com o intuito de aliviar o problema da redução do capital à disposição dos bancos. Além disso, o CMN aprovou, no dia 26 de abril de 2018, uma redução do repasse de contribuição mensal das instituições financeiras ao Fundo Garantidor de Créditos (FGC) de 0,0125 por cento para 0,01 por cento. Esse cálculo é aplicado sobre o montante dos saldos das contas referentes aos instrumentos garantidos, como poupança e CDBs (AYRES, 2018).

A Figura 2 expressa as alterações promovidas pelo BC no período de março de 2017 a março de 2018.

Em entrevista ao Estadão, em abril de 2018, o então presidente do Banco Central do Brasil, Ilan Goldfajn, afirmou que iria "atacar o spread pela raiz". Para ele, "há uma defasagem entre a queda da Selic e do spread, da mesma forma que, quando a Selic sobe, o spread demora mais a subir". Como medidas para essa adequação, Goldfajn destacou as garantias eletrônicas, a diminuição nos custos jurídicos com a reforma trabalhista e a tentativa da aplicação do Cadastro Positivo para o brasileiro, para então diminuir os custos e assim os juros (ZOGBI, 2018). E, para isso, favorecer as pequenas startups que vêm despontando parece ser uma ótima estratégia. 
Figura 2 Alterações promovidas pelo Banco Central entre março de 2017 e março de 2018.

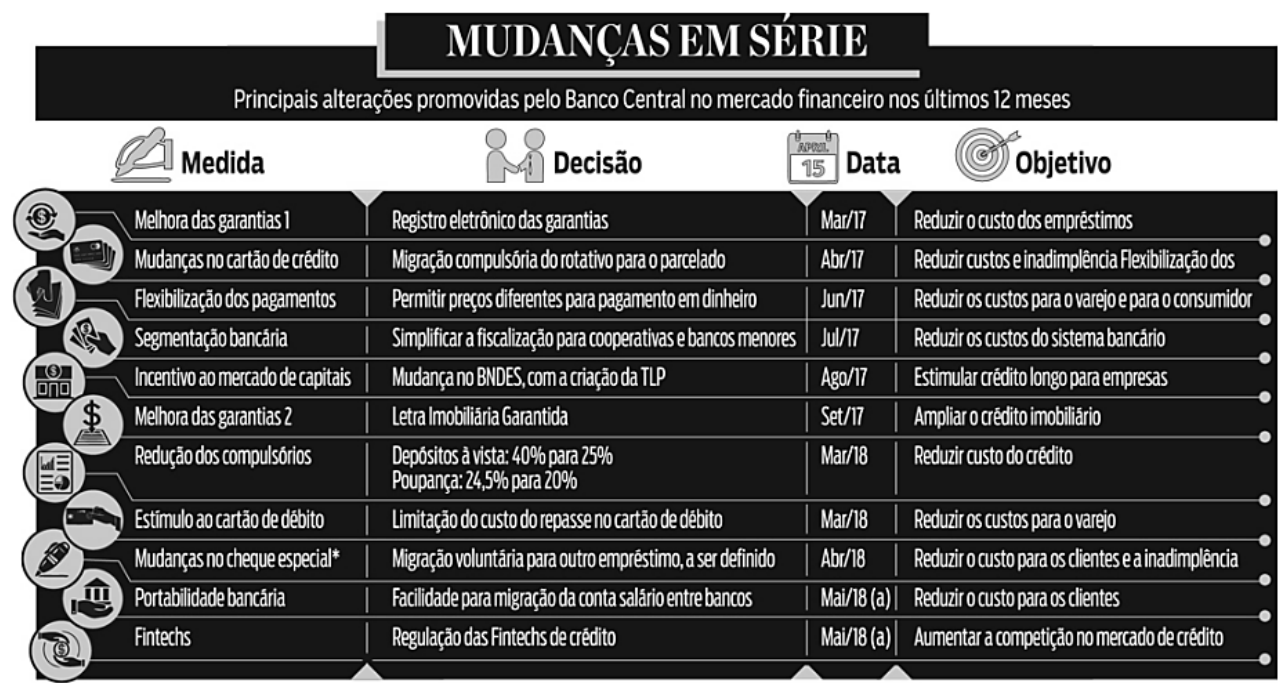

(a) Previsão *Mudança promovida pelos próprios bancos.

Fonte: Gradilone (2018b).

As mudanças de regulação para as fintechs de crédito tiveram o intuito de fomentar a inovação no âmbito do sistema financeiro, aumentar a competição e a concorrência. Sobretudo, novas instituições, mais tecnológicas, vão ajudar a reduzir o custo do crédito e o spread bancário (CAMPOS, 2018). Custo de crédito menor atrai a demanda e promove maior giro da economia. Nas palavras do ex-presidente do BC: "se nós conseguirmos manter essa inflação baixa e o juro baixo, o resto, ao longo do tempo, vai acabar vindo. E, com as medidas que estamos tomando, essa queda é capaz até de vir mais cedo do que se imagina" (GRANDILONE, 2018a).

Por último, evidencia-se que os grandes bancos historicamente vêm sendo privilegiados, pois não enfrentam concorrência senão entre os seus pares. Por outro lado, surgem as startups do setor financeiro, as fintechs, com tecnologia de ponta, que permitem uma penetração mais rápida e efetiva, de juros baixos e o acesso pela população. No final de contas, qual o interesse da relação do governo, em paralelo, com bancos e fintechs? E a partir de agora, quais estratégias as fintechs e os bancos devem tomar? 


\section{ANEXO A - Fintechs atuando no Brasil em 2018}

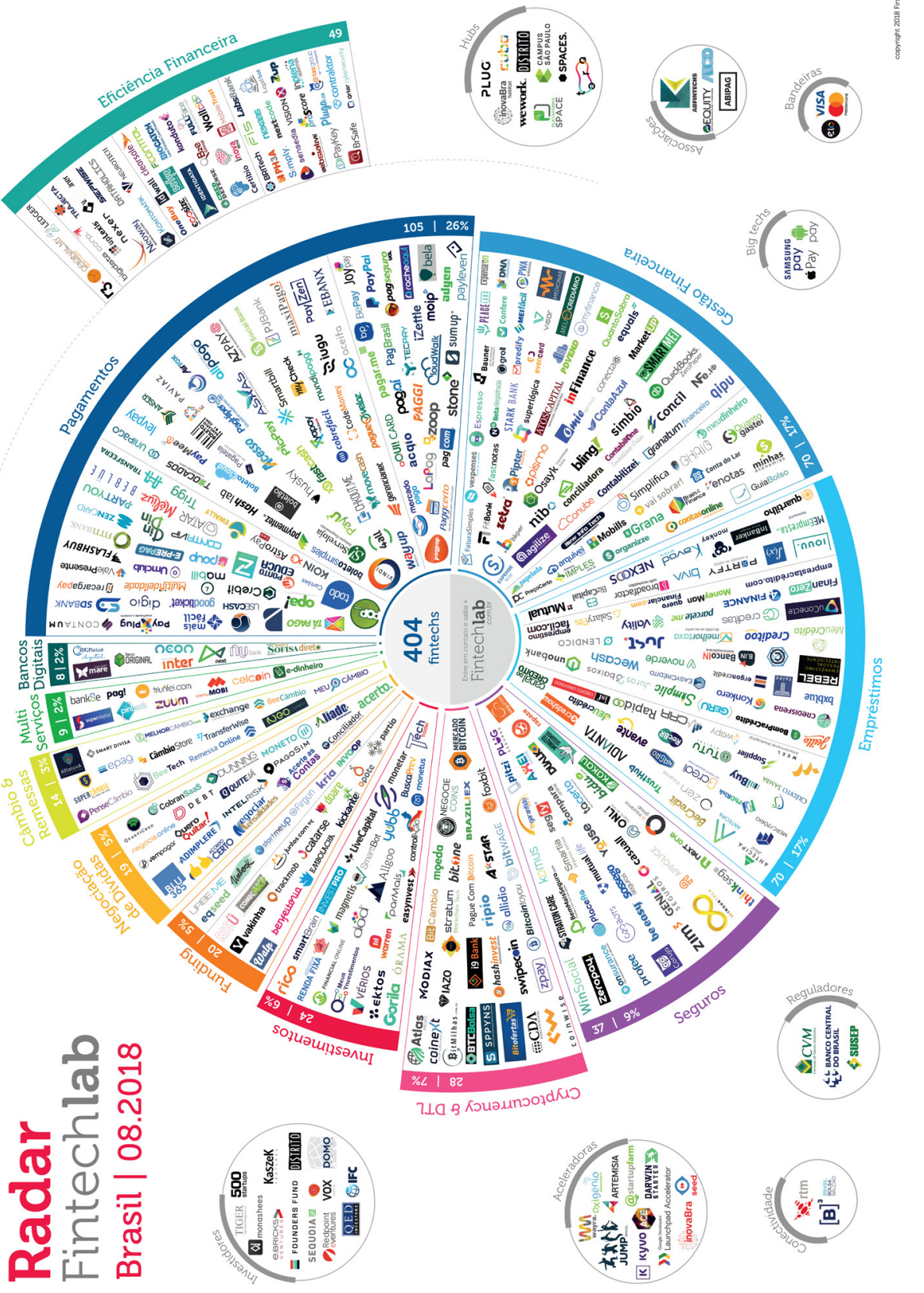

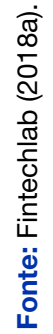




\section{Notas de Ensino}

As notas de ensino são de acesso exclusivo aos docentes. Possuem o objetivo de direcionar o material educacional, estratégias metodológicas e avaliação do caso para ensino.

\section{FONTES DE DADOS}

As fontes dos dados relacionados às empresas, sua origem, evolução histórica, e às pessoas envolvidas no caso foram obtidas por meio de matérias de revistas de circulação nacional e internacional, websites de comunicação e websites das companhias e instituições. Os dados do setor foram obtidos de fontes secundárias, por meio das normativas do Banco Central do Brasil, da Comissão de Valores Mobiliários (CVM), reportagens em revistas (tais como: Exame, Época Negócios, Folha de São Paulo, Forbes Brasil, G1, Infomoney, Reuters, The New York Times e Valor Econômico), páginas da internet, políticas, estatutos e regimentos das empresas.

O período da coleta de dados aconteceu entre 07 de abril e 23 de agosto de 2018. Primeiramente, foram catalogadas digitalmente todas as revistas e matérias jornalísticas que citassem as fintechs brasileiras, os grandes bancos e o governo. Após este processo, capturou-se dessa amostra os trechos que compuseram o caso para ensino. As informações coletadas e transcritas não sofreram adaptações ou inclusões de enredo. O roteiro e acontecimentos são eventos reais. Ainda, o caso foi testado em aulas de graduação e pós-graduação, em universidades do Sul e Sudeste do Brasil. Após os testes, o caso foi aprimorado com base nos comentários, nas sugestões recebidas dos alunos e nas percepções da aplicação pelo docente.

\section{OBJETIVOS EDUCACIONAIS}

O caso apresentado foi construído para discussão em cursos de graduação e pós-graduação em Administração, Ciências Contábeis, Economia e Gestão. Ainda pode ser utilizado em cursos complementares, de curta duração ou educação executiva, nas temáticas como Relações Governamentais e Relações Institucionais. Foi desenvolvido com os objetivos abaixo descritos, visando embasar a discussão teórica do caso e proporcionar, por meio da discussão, o aprendizado acerca de: 
a. analisar as estratégias das fintechs com enfoque nas atividades políticas corporativas sob forma de influenciar o governo e o sistema financeiro nacional;

b. contextualizar a evolução e transformação da economia brasileira, com destaque para o crescimento das fintechs e ruptura do momento de "sossego" dos grandes bancos, além da atuação das duas categorias perante o cenário nacional;

c. discutir as estratégias de mercado concorrenciais dos bancos e das fintechs frente aos cenários futuros possíveis;

d. avaliar a integração das estratégias de mercado e de não mercado, atuando de forma integrativa frente a um interesse comum.

Como requisitos para o total aproveitamento do caso, sugere-se: leitura na íntegra; prévia explicação sobre os conceitos centrais de estratégia de mercado e não mercado; compreensão anterior das teorias de estratégia empresarial; consultar o número de alunos em sala que já utilizam serviços de fintechs e realizar um prévio debate sobre por que as escolheram.

De posse desses elementos, os alunos poderão: compreender as estratégias de mercado e não mercado utilizadas pelas empresas no ambiente competitivo; além de identificar momentos adequados para utilização de estratégias de mercado e não mercado; e a integração de ambas. Ainda, como contribuições práticas: elaborar estratégias de não mercado em suas futuras funções corporativas, e diferenciar estratégias de não mercado das de mercado.

\section{QUESTÕES SUGERIDAS PARA DISCUSSÃO}

As questões apresentadas a seguir podem ser utilizadas com o objetivo educacional de discutir os eixos temáticos, por completo ou em separado, de acordo com a preferência do aplicador do caso.

\section{Eixo 1: Questões sobre estratégias das fintechs e dos bancos:}

a. Aponte quais as principais variáveis, formas pelas quais as fintechs mais ameaçam os grandes bancos e que possibilitam o crescimento dessas startups? 
b. Quais são as estratégias que os bancos tradicionais aplicam nesse cenário?

c. Qual é o objeto da disputa entre fintechs e bancos junto ao Sistema Financeiro Nacional?

\section{Eixo 2: Questões sobre Atividades Políticas Corporativas (APC):}

a. Quais as atividades e/ou ações corporativas políticas que as fintechs têm usado para conseguir ganhar terreno no mercado financeiro brasileiro?

b. Identifique e justifique uma ação individual e uma ação coletiva utilizada pelas fintechs.

c. Quais desafios na relação com o governo enfrentam os bancos? E as fintechs? E como ambos estão respondendo aos desafios?

\section{APLICAÇÃO DO CASO}

Como apoio ao professor na aplicação do caso em sala de aula, apresentam-se duas sugestões de plano de aula. A primeira, na forma de roteiro, separado por seção do caso. Para tanto, faz-se necessária uma leitura atenta ao caso antes da aula. Se isso não for possível, pode-se reservar 20 minutos, no início da sessão, para que os alunos façam a leitura.

O plano de aula (Quadro 1) está baseado em perguntas que podem ser utilizadas pelo professor em cada momento das principais seções do caso. 
Quadro 1 Plano de aula roteirizado.

\section{QUESTÕES}

SEÇÃO

Apresentação geral do caso, detalhando seus objetivos e o dilema.

Resumo

Nesta seção, é importante abordar o contexto político e econômico demonstrado, para então situar os alunos da melhor forma, na compreensão das decisões tomadas e posterior posicionamento nas questões propostas.

1. Qual o cenário do sistema financeiro nacional (SFN) até o Introdução início dos anos 2000 ?

2. Há novos atores financeiros em busca de espaço no mercado?

3. É possível identificar uma mudança estrutural no SFN?

Contexto econômico brasileiro, desde a abordagem de inflação e taxa básica de juros.

1. Atualmente, qual é a estratégia do Banco Central em relação à taxa de juros?

2. Já é imaginável um cenário propício para a entrada de um novo ator financeiro, apoiado pelo governo e pelo Sistema

Redução das taxas de juros: dinheiro para a população Financeiro Nacional?

Abordagem específica para as startups financeiras que estão transformando o ambiente financeiro.

1. As fintechs estão disputando acesso ao mercado com alguns suportes substanciais? Quais?

2. Quais as principais vitórias para as fintechs no sentido de Brasil regulação?

3. É visível o apoio por parte do governo, agência reguladores e SFN? De que forma?

As fintechs penetraram de forma rápida e efetiva e houve diversas formalizações para seu funcionamento dessas startups do setor financeiro. Porém, ambos atores são importantes.

As mudanças em

1. Qual o interesse da relação do governo, em paralelo, com série bancos e fintechs?

2. Quais estratégias as fintechs e os Bancos devem tomar?

Fonte: Elaborado pelos autores. 
Ainda, sugere-se um plano de aula alternativo (Quadro 2), na forma tradicional, o qual promove a discussão do caso de uma forma mais abrangente, levando em consideração o perfil da turma, a quantidade de alunos, entre outras características.

Quadro 2 Plano de aula alternativo.

TEMPO ESTIMADO

\section{ATIVIDADE}

Apresentação geral do caso, detalhando o tema e os embates principais.

Discussão sobre as decisões tomadas pelas par-

30-40min tes do contexto e atores do caso, e o dilema presente no caso.

Sugere-se duas atividades como plano de aula:

1. Dividir a turma em dois grupos: a) um grupo fica responsável por responder como representante das fintechs, e b) o outro grupo representa os grandes bancos.

2. De forma mais complexa, dividir a turma em quatro grupos: a) os responsáveis a respon-

$90-120 \mathrm{~min}$ der pelas fintechs; b) pelos grandes bancos; c) pelo Governo; e d) a sociedade como um todo.

Apresenta-se as questões propostas neste caso e discute-se, cobrando uma ênfase no posicionamento de cada parte já nominada. Ao final, procura-se um desfecho predominante, no qual o professor pode direcionar para o contexto atual no país, aquele no momento da aplicação do caso.

Fechamento da aula com: a) reflexão das ações executadas; b) outras possíveis tomadas de decisão dos atores do caso; e ainda c) prováveis futu20-30min ros acontecimentos espelhados nas regulamentações e decisões observadas. Outras hipóteses de decisões já tomadas também podem ser sugeridas pela turma.
CONCEITOS MOBILIZADOS

Objetivos

Contexto histórico, embate entre os atores e mediação das instituições.

Estratégia de mercado

Atividades Políticas Corporativas

Estratégia integrada

Decisões das fintechs e dos bancos, com base no objetivo perseguido pelo governo de recuperação econômica.

Fonte: Elaborado pelos autores. 


\section{DIRECIONAMENTO DE RESPOSTAS PARA AS QUESTÕES SUGERIDAS}

\section{Eixo 1:}

a. A crise financeira global anunciou um período prolongado de programas de transformação. Muitas fintechs estão abraçando este ciclo. O abraço dado pelas fintechs não abarca somente tecnologia, mas inclui cultura, formas de trabalho, solução de problemas, envolvimento do cliente e novas ideias de liderança. Essas startups estão colocando a disrupção no centro de sua estratégia (PWC, 2017).

A estratégia deve ser determinada antes da escolha da tecnologia, da contratação de pessoas e do cultivo de clientes (BESANKO et al., 2012). As startups especializadas em tecnologia financeira, ou "fintechs", chamaram a atenção nos últimos anos pelo desenvolvimento de soluções para os gargalos nos mecanismos financeiros tradicionais. Plataformas de análises avançadas estão aproveitando big data retirados de rastros digitais para conduzir avaliações de crédito mais rápidas. Por meio das tecnologias digitais, estas empresas estão ajudando a criar perfis de risco de crédito mais robustos e a melhorar a compreensão do complexo mercado das Micro, Pequenas e Médias Empresas (MPME). A automação digital pode agilizar os processos de subscrição, bem como a tomada de decisão organizacional, reduzindo assim os custos para as instituições financeiras.

As micro, pequenas e médias empresas (MPME) são consideradas de importância estratégica para as instituições financeiras da América Latina e do Caribe (ALC). Podem fortalecer esse ambiente de apoio reconfigurando estratégias para entrar em novos mercados na ALC, levando em consideração não apenas as peculiaridades da região, mas também os incentivos e motivações de negócio das instituições financeiras locais (HODER et al., 2016).

Fintechs têm desenvolvido aplicações inovadoras para os mercados financeiros e muitas delas têm sido bem-sucedidas em oferecer de forma independente inúmeros serviços tradicionalmente prestados por instituições financeiras. Ao alavancar as tecnologias digitais, as fintechs encontram maneiras inovadoras de melhorar o serviço ao cliente, levantar capital, facilitar os pagamentos eletrônicos e analisar grandes volumes de dados. As fintechs são mais ágeis do que as insti- 
tuições financeiras tradicionais, adaptando-se mais rapidamente às necessidades do mercado. Em sua a maioria são startups, atualmente ainda não submetidas à mesma carga regulatória que os bancos. Isso afeta os bancos tradicionais, de forma que estes precisam reconhecer as suas diferenças em relação às fintechs, a fim de desenvolverem estratégias digitais bem informadas.

Os serviços bancários móveis e on-line, combinados com as técnicas de empréstimo de transações, permitem o acesso contínuo a serviços bancários em grandes distâncias. Maior confiança em informações difíceis e quantificáveis disponíveis on-line e através de agências de crédito facilitam a tomada de decisões com base na inteligência artificial (JAKŠıČ; MARINČ, 2018).

b. Os bancos optaram grandemente pela segmentação de seus produtos. Empresas que buscam crescimento através da ampliação de sua indústria podem conter melhor os riscos com a estratégia criando unidades independentes, cada uma com seu próprio nome de marca e atividades sob medida.

Especialmente nos grandes bancos dominantes do cenário brasileiro, há uma rede de relacionamento pessoal, que gera maior confiança do mercado, além dos múltiplos serviços oferecidos com certa tecnologia avançada, e o contato humano ainda importa para uma faixa significante de clientes. Algumas ações, como baixar preços e lançar plataformas similares para concorrer (até mesmo cooperativas já estão lançando), levam à estratégia competitiva, aquela que tem a ver com ser diferente. Tais ações significam escolher deliberadamente um conjunto diferente de atividades para distribuir um mix único de valor (PORTER, 1996).

As instituições financeiras procuram responder adequadamente às inovações e, assim, capacitar seus clientes diariamente. Abordar a retenção de clientes no contexto da nova competição exigirá que os bancos tradicionais se concentrem primeiramente no desenvolvimento de design intuitivo de produtos, facilidade de uso e acessibilidade 24 horas por dia, sete dias por semana. As instituições financeiras também precisarão interromper suas próprias operações ou processos, o que introduzirá desafios culturais e de mentalidade (PWC, 2017). 
A vantagem competitiva e a mudança organizacional tendem a convergir em função das rápidas mudanças econômicas e sociais advindas da evolução dos ambientes organizacionais. A vantagem competitiva é um acidente excepcional, imperfeição temporária do funcionamento do Mercado. A firma apenas aplica mecanicamente as regras do cálculo econômico, que é representado pela transformação de insumos em produtos. São dois eixos: a) como atributo de posicionamento, exterior à organização, e b) a performance superior como um fenômeno decorrente das características internas. Porter utiliza como unidade de análise a indústria, e não a firma individual. O posicionamento da firma dentro da estrutura industrial é o principal determinante de sucesso ou fracasso. Vantagem competitiva é resultado da firma de realizar eficientemente o conjunto de atividades necessárias para obter um custo mais baixo que o dos concorrentes, ou gerar valor diferenciado para os compradores. A estratégia, assim, tem papel de proteger a firma das forças competitivas (VASCONCELOS; CYRINO, 2000).

À medida que as concorrentes imitam as melhorias umas das outras, em termos de qualidade, tempos de ciclo ou parcerias com fornecedores, as estratégias convergem e a competição se torna uma série de corridas em pistas idênticas, onde não há vencedora. Estratégia competitiva tem a ver com ser diferente. Novos entrantes podem prosperar ocupando uma posição que um concorrente deteve em outra ocasião, mas da qual abriu mão devido aos anos de imitação e indecisão (PORTER, 1996).

c. A disputa entre os dois atores principais do caso é o mercado. E as estratégias são as formas pelas quais se chegará a obter a fatia de mercado desejada.

Em 1979, Michael Porter começou uma revolução no campo da estratégia. Nas décadas seguintes, Porter trouxe seu rigor econômico para o estudo da concorrência estratégica como alternativa para as empresas.

Em essência, o trabalho do estrategista é compreender que se deve ficar e enfrentar a concorrência. Muitas vezes, os gestores definem competição muito estreitamente, como se isso ocorresse apenas entre concorrentes diretos. No entanto, a concorrência para obter lucros vai além dos rivais do setor, inclui outras 
quatro forças competitivas: clientes, fornecedores, potenciais entrantes, e produtos/serviços substitutos (Figura 3). Sobretudo, neste caso entre fintechs e bancos tradicionais, a disputa ocorre devido à força da ameaça de novos entrantes, neste cenário, as fintechs.

Figura 3 Cinco forças competitivas de Porter.

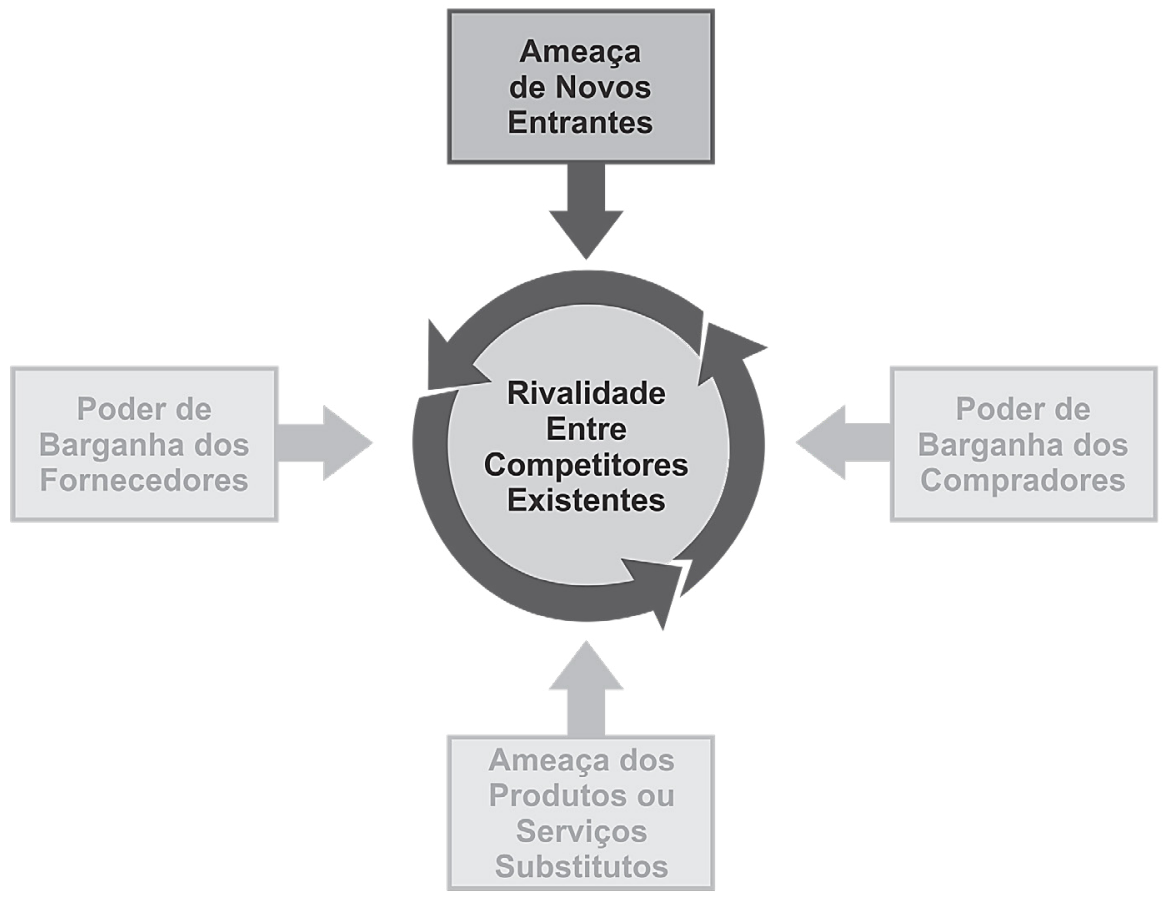

Fonte: Porter (2008).

A ameaça de entrada está relacionada às barreiras de entrada e ao resultado da interação dos competidores (novos ou não) com essas barreiras. Especialmente neste caso de disputa entre as fintechs e os bancos tradicionais, a barreira de entrada associada é a política governamental restritiva. Um maior monitoramento do mercado e instituições de melhor qualidade está associado a uma maior concentração de mercado e a maiores taxas de crescimento de bancos mais eficientes. $E$ as restrições de entrada mais rigorosas estão associadas a uma maior concentração e participação de mercado (GONZÁLEZ, 2009). 
Para abrir um banco, há a necessidade de várias liberações no âmbito legal e de licenças que devem ser expedidas. Essas regulamentações rígidas, pelas agências do governo, para alguns setores são exemplos de barreiras de entrada típicos. É diferente de abrir um restaurante ou um comércio varejista, alguns segmentos de mercado, além dos bancos, também companhias de seguros e hospitais precisam de uma fiscalização mais ampla para proteger a sociedade, o que torna a entrada nesses mercados mais difícil.

Em suma, o governo, por meio da política, pode prejudicar ou ajudar a nova entrada diretamente, bem como amplificar (ou anular) a barreira de entrada. De acordo com sua necessidade, o governo limita diretamente ou mesmo prevê um fechamento da entrada em determinados setores, com requisição de licenciamento e restrições sobre o investimento estrangeiro. A política do governo pode também aumentar outras barreiras de entrada através de regras de patenteamento, que protegem tecnologia proprietária da imitação ou normas ambientais, ou de segurança, que aumentam economias de escala voltadas para os recém-chegados (PORTER, 2008).

O uso estratégico das ações de mercado pode permitir que as empresas tenham uma influência significativa sobre a política. Podem ser usadas ações de mercado, ou apenas a ameaça, como alavanca para empenhar os formuladores de políticas a criar ou revogar regras específicas (FUNK; HIRSCHMAN, 2017). Dito isto, relata-se, no eixo 2 , como as empresas se protegem de interferências políticas indesejadas e obtêm acesso e apoio de atores e instituições políticas, e ainda, como influenciam a política ou processo governamental, especialmente para conseguir acesso ao mercado.

\section{Eixo 2:}

a. A CPA é um subcampo da estratégia de não mercado que estuda as ações políticas das empresas no ambiente regulatório (GETZ, 1997; BODDEWYN, 2007). Ela é definida por Hillman, Keim e Schuler (2004, p. 837) como as "tentativas corporativas de moldar a política governamental". $\mathrm{Na}$ abordagem da economia política, a CPA é considerada essencial para influenciar políticas econômicas em favor dos interesses comerciais. 
As fintechs utilizaram a contratação de ex-político, no caso do Gustavo Franco. Assim como, no desenvolvimento de uma nova fintech, liderada pelo ex-ministro da fazenda, Henrique Meirelles. Ainda, utilizaram a associação a entidades de classe, por meio das quais se organizaram para melhor se articular junto aos órgãos reguladores. Nesse sentido, foram formadas a Associação Brasileira de Fintechs (ABFintechs), a Associação Brasileira de Crédito Digital (ABCD), e ainda, a Associação Brasileira de Equity Crowdfunding, estabelecida às vésperas da regulamentação do financiamento coletivo pela Comissão de Valores Mobiliários (CVM) em 2016. (NERY, 2016).

Historicamente, a regulamentação era vista como uma barreira à entrada no setor de bancos. Os requisitos eram complexos, pesados e difíceis para as novas organizações pequenas adotarem. Agora observa-se o reverso. Muitos dos bancos tradicionais são prejudicados por processos complexos e pela governança que criaram em torno do risco e da regulamentação, e muitos também desenvolveram um grau significativo de aversão ao risco. Este ambiente é propício para que a inovação influencie o setor de serviços financeiros (PWC, 2017).

Os reguladores também estão procurando formas de alavancar novas tecnologias e análises, para gerenciar melhor o risco sistêmico e grandes quantidades de dados (PWC, 2017). Desta forma, abrem-se brechas para execução das atividades políticas corporativas. Por outro lado, além de proteger as empresas da pressão externa, a CPA proporciona às empresas benefícios de políticas públicas e uma forma de seguro político que pode isolar as empresas do impacto negativo, especialmente quando há uma postura não cooperativa por parte do governo. O apoio vem em forma de recursos e capacidades políticas, que resultam em ações tomadas pelo governo ou suas agências para proteger as empresas de forças externas indesejadas, tornando-se, assim, uma atividade lucrativa que as ajuda a "comprar" favores do governo e, portanto, reduzir sua necessidade de esforço para com as pressões externas. (HADANI; DOH; SCHNEIDER, 2019).

b. Individual: Ao compor um cargo de alto gerenciamento em uma empresa, o ex-político pode facilitar a comunicação entre os shareholders e os reguladores. Para o governo, essa ligação também é importante, pois empresas, por exemplo, de setores regulados, normalmente pertencem a se- 
tores fundamentais na economia. Além disso, torna a empresa mais confiável para o mercado, que entende a nomeação do ex-político como algo positivo para a organização, que terá mais apoio da agência reguladora.

Dorobantu, Kaul e Zelner (2017) chancelam a utilização dessa estratégia por assegurar que a escolha das empresas por mecanismos políticos possui o foco de influenciar o poder público. No estudo de Hambrick, Misangyi e Park (2015), a ação política da empresa que estabelece um tipo de vínculo interorganizacional entre uma empresa e o governo é quando um membro da equipe de gerenciamento sênior ou o conselho de administração começa a servir em uma posição política nomeada ou eleita. Comumente são vistas pesquisas que utilizam conselheiros conectados politicamente (BROWN, 2016a; BROWN, 2016b; KUO; YU, 2017). Em contraponto, ex-funcionários do governo ou alguém que foi nomeado para órgão público, é unidade de pesquisa de Zhang, Marquis e Qiao (2016), que corroboram que executivos com conexões políticas alcançadas podem ter melhor compreensão e maior informação sobre a preocupação do governo, logo, possuem um alinhamento de interesses. Sobretudo, o ex-político tem o papel de facilitar a relação entre shareholders e reguladores (BOUBAKRI; COSSET; SAFFAR, 2008), exercer maior pressão nos reguladores para obter apoio político (HOLBURN; VANDEN BERGH, 2008), e o governo também tem interesse nessa proximidade, uma vez que há setores importantes na economia nacional (BOUBAKRI; COSSET; SAFFAR, 2008). Ainda, Lock e Seele (2016) utilizam, como uma das variáveis de conexão de atividade política corporativa, aqueles gerentes com participação em partido político. Neste caso, Gustavo Franco é filiado ao Partido Novo.

Coletiva: Para Baron (1999), uma estratégia de não mercado pode envolver ações coletivas tomadas com rivais do mercado, outras indústrias ou grupos de interesse. As estratégias individuais de não mercado das empresas reduzem a rigidez do regulamento, mas não são tão eficazes como a NMS, que a indústria escolheria se fosse organizada como uma coalizão que atuasse em nome de seus membros.

As empresas que já são membros de uma associação política coletiva chave são mais propensas a ter interesse em ação política. Esse movimento é mais forte em províncias menos desenvolvidas economicamente (JIA, 2014). 
Ações políticas proativas por parte das empresas são como informar os decisores governamentais sobre o impacto de uma possível legislação; tentar reduzir ativamente a regulamentação governamental da empresa; trabalhar sozinho ou em associações comerciais para fazer contribuições de campanha ou influenciar de outra forma os processos legislativos e/ou regulatórios (HILLMAN; KEIM; SCHULER, 2004). As corporações podem aumentar suas atividades políticas por meio da coordenação com associações comerciais e/ou coalizões via advogados ou escritórios de advocacia (MACK, 1997). As associações comerciais geralmente representam um amplo espectro de membros da indústria. Esses tipos de associações são mais susceptíveis de serem politicamente ativos durante a formulação de políticas quando seus membros têm preocupações semelhantes sobre a legislação proposta (MACK, 1997; ROBERTS; DWYER; SWEENEY, 2003).

c. Os bancos estão esperando para retornar aos níveis de rentabilidade pré-crise, mas os desafios políticos, sociais, econômicos, regulatórios, competitivos e tecnológicos continuam a exercer pressão negativa sobre o desenvolvimento de seus negócios.

Com os métodos regulatórios iniciais para estabilizar a economia e o desempenho do setor bancário, os participantes do mercado procuram aumentar a penetração no mercado, encontrando novos canais para satisfazer as necessidades dos clientes em serviços financeiros, surgindo assim as fintechs. Justamente, a principal área para aplicar essa transformação é o negócio de banco de varejo, que fornece uma função econômica vital e tem impacto significativo sobre os consumidores e as pequenas e médias empresas do país. Isso é, diretamente, através do fornecimento de produtos bancários transacionais, produtos de poupança e empréstimos, e indiretamente, através do impacto que os consumidores e as pequenas e médias empresas têm na economia real (SLOBODA; DUNAS; LIMAŃSKI, 2018).

O impulso no setor vem na sequência da melhora da economia brasileira, com recuperação da atividade, controle da inflação e juros em níveis recordes de baixa, o que estimula a busca de maior rentabilidade por investidores, com o mercado de capitais oferecendo um leque de opções. O Banco Central conhece bem a tragédia que aqui se descreve e, por isso, não imprime dinheiro à toa. Se a inflação 
aumenta, a forma de tentar controlá-la é subir os juros e reduzir a quantidade de moeda em circulação. Também há maneiras mais "criativas" de fazer isso, como tabelar ou congelar preços e confiscar a renda da população, mas costumam fracassar, como os casos presentes na descrição do caso.

À medida que os inovadores procuram aproveitar os benefícios externos ao buscar colaboração, a busca por uma estratégia colaborativa pode resultar em mudanças irreversíveis nas características sistêmicas do processo de inovação. Logo, pode haver a necessidade de colaboração entre os bancos. O modelo de inovação presente é eficaz e útil. Ele não apenas expande o conhecimento na área de inovações financeiras, mas também aponta a relação entre as complexidades tecnológicas e as estratégias utilizadas para impulsionar as inovações em direção a um mercado competitivo com amplo uso. Os bancos podem aprender as lições de natureza sistêmica das inovações baseadas nas fintechs, bem como a dinâmica do setor bancário, para buscar estratégias apropriadas à competição de mercado (WONGLIMPIYARAT, 2017).

Por outro lado, os bancos de relacionamento tradicionais ainda podem ter vantagem quando competirem com fintechs. Apesar dos benefícios destas últimas, os dados são propensos à manipulação. As técnicas por trás dos dados também podem não captar corretamente os incentivos de banqueiros. Também levar ao aumento do risco sistêmico ou, ainda, podem desconsiderar as dimensões éticas nos empréstimos. Os relacionamentos fortes ainda apresentam uma vantagem competitiva no setor bancário. Os benefícios de uma rede de agências que se originam da proximidade geográfica e cultural dos clientes dos bancos ainda existem e, em empréstimos, os banqueiros humanos não podem ser totalmente substituídos por computadores artificialmente inteligentes. Os bancos tradicionais precisam adotar a tecnologia, ajustar-se às necessidades dos clientes em mudança e responder às demandas regulatórias (JAKŠIČ; MARINČ, 2018).

Por fim, é notório que a tecnologia está mudando radicalmente a forma como os dois atores interagem com seus respectivos clientes. Ofertas e relacionamentos se tornarão cada vez mais integrados com automação, digitalização, dispositivos inteligentes e interação virtual. Os bancos de varejo serão forçados a migrar agressivamente os clientes para os canais digitais, a fim de competirem. A relação banco-cliente será, portanto, com toda a probabilidade, definida ao longo da dinâ- 
mica de interações remotas, especialmente entre as gerações mais jovens, mais conhecedoras de tecnologia. Além disso, a riqueza de informações sobre os clientes permitirá que os bancos os classifiquem e os segmentem além de observar meras informações biográficas e financeiras, incluindo soluções financeiras médicas e até relacionadas à saúde. Isso permitirá aos bancos fornecer soluções bancárias que não sejam meramente reativas, mas preventivas - isto é, que abram e capitalizem as oportunidades antes que os concorrentes tenham acesso a elas (COETZEE, 2018).

\section{Referências}

ALVES, A. Fintechs se multiplicam com BC e CVM atentos e regulação precária. Exame, 03 mar. 2017 a. Disponível em <https://exame.abril.com.br/pme/fintechs-se-multiplicam-com-bc-e-cvm-atentos-e-regulacao-precaria/>. Acesso em: 07 abr. 2018.

. Fintech Creditas capta R\$ 165 milhões em aporte liderado pelo fundo sueco Vostok. Exame, 11 dez. 2017b. Disponível em <https://exame.abril.com.br/pme/fintech-creditas-capta-r165mi-em-aporte-liderado-por-fundo-sueco/>. Acesso em: 04 jul. 2018.

. Decreto de Temer autoriza Nubank a ter financeira. Notícias de Tecnologia. Reuters, 22 jan. 2018. Disponível em: <https://br.reuters.com/article/internetNews/idBRKBN1FB2TF-OBRIN>. Acesso em 04 abr. 2018a.

ANBIMA - Associação Brasileira das Entidades dos Mercados Financeiros e de Capitais. Juros a 1 dígito. E agora? Disponível em: <http://materiais.anbima.com.br/juros-a-um-digito-ebook/? ga=2.159383418.1112820781.1508171401-1281154336.1505399109>. Acesso em: 26 jul. 2017.

ARROYO, P. David contra os Golias. Isto É Dinheiro, 20 mar. 2018. Disponível em: <www.istoedinheiro. com.br/david-contra-os-golias/>. Acesso em: 27 abr. 2018.

AYRES, M. BC reduz contribuição mensal dos bancos ao FGC e espera repasse de economia para consumidor. Notícias de Negócios. Reuters, 26 abr. 2018. Disponível em: <https://br.reuters.com/article/ businessNews/idBRKBN1HX3AK-OBRBS>. Acesso em: 27 abr. 2018.

BARON, D. P. Integrated market and nonmarket strategies in client and interest group politics. Business and Politics, v. 1, n. 1, p. 7-34, 1999. DOI: 10.1515/bap.1999.1.1.7.

BESANKO, D.; DRANOVE, D.; SHANLEY, M.; SCHAEFER, S. A economia da estratégia. $5^{\text {a }}$ ed. Porto Alegre: Bookman, 2012.

BNDES - Banco Nacional de Desenvolvimento Social. BNDES lança Fundo de Coinvestimento Anjo em startups brasileiras inovadoras. Mercado de Capitais. Inovação. BNDES, 14 nov. 2017. Disponível em: <www.bndes.gov.br/wps/portal/site/home/imprensa/noticias/conteudo/bndes-lanca-fundo-de-coinvestimento-anjo-em-startups-brasileiras-inovadoras>. Acesso em: 12 abr. 2018.

BODDEWYN, J. J. The internationalization of the public-affairs function in U.S. multinational enterprises. Business \& Society, v. 46, n. 2, p. 136-173, 2007. DOI: 10.1177/0007650307301381. 
Um Olho no Peixe e Outro no Gato: Como as Fintechs Disputam Espaço com os Bancos em Época de Juros Baixos An Eye on the Fish and Another on the Cat: How the Fintechs Dispute Space with the Banks in Times of Low Interest Raul Beal Partyka | Jeferson Lana | Marina Amado Bahia Gama

BOUBAKRI, N.; COSSET, J. -C.; SAFFAR, W. Political connections of newly privatized firms. Journal of Corporate Finance, v. 14, n. 5, p. 654-673, 2008. DOI: 10.1016/j.jcorpfin.2008.08.003.

BRASIL. (2016). Ministério da Fazenda. Comissão de Valores Mobiliários-CVM. Portaria CVM/PTE N 105, de 07 de junho de 2016. Institui o Núcleo de Inovação em Tecnologias Financeiras da CVM. CVM, Rio de Janeiro, RJ, 07 de junho de 2016.

. (2018a). Ministério da Fazenda. Banco Central do Brasil. Resolução N. 4.649 de 28 de março de 2018. Dispõe sobre a prestação de serviços por parte de instituições financeiras a instituições de pagamento e a outras instituições autorizadas a funcionar pelo Banco Central do Brasil. Publicado no Diário Oficial da União de 02 de abril de 2018. Disponivel em: <http://www.lex.com.br/legis_27631327_RESOLUCAO_N_4649_DE_28_DE_MARCO_DE_2018.aspx> Acesso em: 21 abr. 2018.

. (2018b). Presidência da República. Decreto № 9.283, de 7 de fevereiro de 2018. Regulamenta a Lei $n^{\circ} 10.973$, de 2 de dezembro de 2004, a Lei $n^{\circ} 13.243$, de 11 de janeiro de 2016, o art. 24 , $\S 3^{\circ}$, e o art. 32, $\S 7^{\circ}$, da Lei $n^{\circ} 8.666$, de 21 de junho de 1993, o art. $1^{\circ}$ da Lei $n^{\circ} 8.010$, de 29 de março de 1990 , e o art. $2^{\circ}$, caput, inciso I, alínea "g", da Lei $n^{\circ}$ 8.032, de 12 de abril de 1990, e altera o Decreto ${ }^{\circ} 6.759$, de 5 de fevereiro de 2009, [...]. Publicado no Diário Oficial da União de 08.02.2018. Disponível em: <www. planalto.gov.br/ccivil_03/_Ato2015-2018/2018/Decreto/D9283.htm> Acesso em: 21 abr. 2018.

(2018c). Presidência da República. Ministério do Trabalho. Lei n 13.636, de 20 de março de 2018. Dispõe sobre o Programa Nacional de Microcrédito Produtivo Orientado (PNMPO); e revoga dispositivos das Leis nos 11.110, de 25 de abril de 2005, e 10.735, de 11 de setembro de 2003. Diário Oficial da União, Brasília, DF, n. 55, 21 mar. 2018.

BROWN, R. S. AT\&T's establishment of a political capability. Journal of Public Affairs, v. 16, n. 1, p. 57-65, 2016a. DOI: 10.1002/pa.1568.

. How do firms compete in the non-market? The process of political capability building. Business and Politics, v. 18, n. 3, p. 263-295, 2016b. DOI: 10.1515/bap-2015-0019.

CAMPOS, E. CMN regulamenta fintechs para atrair participação de instituições. Valor Econômico, 26 abr. 2018. Disponível em: < www.valor.com.br/financas/5486409/cmn-regulamenta-fintechs-para-atrair-participacao-de-instituicoes>. Acesso em: 27 abr. 2018.

COETZEE, J. Strategic implications of Fintech on South African retail banks. South African Journal of Economic and Management Sciences, v. 21, n. 1, p. 1-11, 2018.

DOROBANTU, S.; KAUL, A.; ZELNER, B. Nonmarket strategy research through the lens of new institutional economics: An integrative review and future directions. Strategic Management Journal, v. 38, n. 1, p. 114-140, 2017. DOI: 10.1002/smj.2590.

'FINTECHS' PODEM entrar na rede de empréstimos do BNDES. Estadão Conteúdo / Infomoney, 18 jul. 2017. Disponível em: <www.infomoney.com.br/minhas-financas/credito/noticia/6803422/fintechs-podem-entrar-rede-emprestimos-bndes $>$. Acesso em: 08 abr. 2018.

FINTECHS CRESCEM com apoio de órgãos de fomento. Forbes Brasil, 25 ago. 2017. Disponível em: <https://forbes.uol.com.br/negocios/2017/08/fintechs-crescem-com-apoio-de-orgaos-de-fomento/>. Acesso em: 12 abr. 2018.

FINTECHS CAMINHAM para consolidação, diz presidente da ABFintechs. Época Negócios online, 28 jun. 2018. Disponível em: <https://epocanegocios.globo.com/Tecnologia/noticia/2018/06/fintechs-caminham-para-consolidacao-diz-presidente-da-abfintechs.html>. Acesso em: 28 jun. 2018. 
Um Olho no Peixe e Outro no Gato: Como as Fintechs Disputam Espaço com os Bancos em Época de Juros Baixos An Eye on the Fish and Another on the Cat: How the Fintechs Dispute Space with the Banks in Times of Low Interest Raul Beal Partyka | Jeferson Lana | Marina Amado Bahia Gama

FINTECHLAB. Novo Radar FintechLab mapeia mais de 400 iniciativas. 13 ago. 2018a. Disponível em: $<$ https://fintechlab.com.br/index.php/2018/08/13/novo-radar-fintechlab-mapeia-mais-de-400-iniciativas/>. Acesso em: 23 ago. 2018.

Fintechs defendem aprovação do Cadastro Positivo em audiência no Senado. 25 apr. 2018b. Disponível em: <https://fintechlab.com.br/index.php/2018/04/25/fintechs-defendem-aprovacao-do-cadastro-positivo-em-audiencia-no-senado/>. Acesso em: 28 jun. 2018.

. Decreto permite a universidades e empresas públicas serem sócias de startups. 09 fev. 2018c. Disponível em: <https://fintechlab.com.br/index.php/2018/02/09/decreto-permite-a-universidades-e-empresas-publicas-serem-socias-de-startups/>. Acesso em: 28 jun. 2018.

. Presidente do BC afirma que fintechs só serão reguladas quando se desenvolverem. 06 mar. 2018d. Disponível em: <https://fintechlab.com.br/index.php/2018/03/06/presidente-do-bc-afirma-que-fintechs-so-serao-reguladas-quando-se-desenvolverem/>. Acesso em: 07 abr. 2018.

. Conta-salário poderá ser transferida para fintechs sem tarifas em julho. 26 fev. 2018e. Disponível

em: <https://fintechlab.com.br/index.php/2018/02/26/contas-salarios-poderao-ser-transferidas-para-fintechs-sem-tarifas-em-julho/>. Acesso em: 07 abr. 2018.

FRIEDLANDER, D. Meirelles relança na internet banco Original, de donos da JBS. Folha de São Paulo, 29 mar. 2016. Disponível em: <www1.folha.uol.com.br/mercado/2016/03/1754983-meirelles-relanca-na-internet-banco-original-de-donos-da-jbs.shtml>. Acesso em: 28 jun. 2018.

FUNK, R. J.; HIRSCHMAN, D. Beyond nonmarket strategy: market actions as Corporate Political Activity. Academy of Management Review, v. 42, n. 1, p. 32-52, 2017. DOI: 10.5465/amr.2013.0178.

GETZ, K. A. Research in Corporate Political Action. Business \& Society, v. 36, n. 1, p. 32-72, 1997. DOI: 10.1177/000765039703600103.

GONZÁLEZ, F. Determinants of bank-market structure: efficiency and political economy variables. Journal of Money, Credit and Banking, v. 41, p. 735-754, 2009. DOI: 10.1111/j.1538-4616.2009.00229.x.

GRADILONE, C. "Gostaria que essas taxas caíssem ainda mais rápido". Isto É Dinheiro, 13 abr. 2018a. Disponível em: < https://www.istoedinheiro.com.br/gostaria-que-essas-taxas-caissem-ainda-mais-rapido/>. Acesso em: 27 abr. 2018.

. A cruzada de llan Goldfajn contra os juros altos. Isto É Dinheiro, 13 abr. 2018b. Disponível em: $<w w w . i s t o e d i n h e i r o . c o m . b r / a-c r u z a d a-d e-i l a n-g o l d f a j n-c o n t r a-o s-j u r o s-a l t o s />$. Acesso em: 27 abr. 2018.

HADANI, M.; DOH, J. P.; SCHNEIDER, M. Social movements and corporate political activity: Managerial responses to socially oriented shareholder activism. Journal of Business Research, v. 95, n. February, p. 156-170, 2019. DOI: 10.1016/j.jbusres.2018.10.031.

HAMBRICK, D. C.; MISANGYI, V. F.; PARK, C. A. The quad model for identifying a corporate director's potential for effective monitoring: Toward a new theory of board sufficiency. Academy of Management Review, v. 40, n. 3, p. 323-344, 2015. DOI: 10.5465/amr.2014.0066.

HILLMAN, A. J.; KEIM, G. D.; SCHULER, D. Corporate political activity: A review and research agenda. Journal of Management, v. 30, n. 6, p. 837-857, 2004. DOI: 10.1016/j.jm.2004.06.003.

HODER, F.; WAGNER, M., SGUERRA, J.; BERTOL, G. A revolução fintech: como as inovações digitais estão impulsionando o financiamento às MPME na América Latina e Caribe. Oliver Wyman / Cll Corpora- 
Um Olho no Peixe e Outro no Gato: Como as Fintechs Disputam Espaço com os Bancos em Época de Juros Baixos An Eye on the Fish and Another on the Cat: How the Fintechs Dispute Space with the Banks in Times of Low Interest Raul Beal Partyka | Jeferson Lana | Marina Amado Bahia Gama

ção Interamericana de Investimentos, 2016. Disponível em: <www.iic.org/sites/default/files/documents/ pub/pt/cii_-_oliver_wyman_-_a_revolucao_fintech_0.pdf>. Acesso em: 28 jun. 2018.

HOLBURN, G. L. F.; VANDEN BERGH, R. G. Making friends in hostile environments: political strategy in regulated industries. Academy of Management Review, v. 33, n. 2, p. 521-540, 2008. DOI: 10.5465/ amr.2008.31193554.

JAKŠIČ, M.; MARINČ, M. Relationship banking and information technology: The role of artificial intelligence and FinTech. Risk Management, p. 1-18, 2018. DOI: 10.1057/s41283-018-0039-y.

JIA, N. Are collective political actions and private political actions substitutes or complements? Empirical evidence from China's private sector. Strategic Management Journal, v. 35, p. 292-315, 2014. DOI: 10.1002/smj.2092.

KUO, L.; YU, H. -C. Corporate political activity and environmental sustainability disclosure: The case of Chinese companies. Baltic Journal of Management, v. 12, n. 3, p. 348-367, 2017. DOI: 10.1108/BJM-072016-0149.

LAIER, P. A. Fintech Toro Investimentos lança corretora neste semestre após aporte de $\mathrm{R} \$ 46 \mathrm{mi}$. Reuters, 27 mar. 2018. Disponível em: <https://br.reuters.com/article/internetNews/idBRKBN1H31TI-OBRIN>. Acesso em: 12 abr. 2018.

LEAHY, J. Brazilian start-ups defy economic gloom with record fundraisings. Financial Times, 4 jul. 2018. Disponível: <www.ft.com/content/8742a6b2-7b18-11e8-bc55-50daf11b720d> Acesso em: 11 jul. 2018. LOCK, I.; SEELE, P. Deliberative lobbying? Toward a noncontradiction of Corporate Political Activities and Corporate Social Responsibility? Journal of Management Inquiry, v. 25, n. 4, p. 415-430, 2016. DOI: 10.1177/1056492616640379.

MACK, C. Business, politics, and the practice of government relations. Westport, CT: Quorum Brooks, 1997.

MANDL, C. Banco Inter espera levantar até 816 milhões de reais em IPO. Reuters, 05 abr. 2018. Disponível em: <https://br.reuters.com/article/businessNews/idBRKCN1HC2JQ-OBRBS>. Acesso em: 12 abr. 2018.

MIOZZO, J. Não existe diferença entre banco e fintech, diz presidente do Santander no Brasil. Infomoney, 27 out. 2017. Disponível em: <www.infomoney.com.br/negocios/grandes-empresas/noticia/7040885/ nao-existe-diferenca-entre-banco-fintech-diz-presidente-santander-brasil>. Acesso em: 07 abr. 2018.

NERY, C. Fintechs se organizam para crescer. Valor Econômico, 21 nov. 2016. Disponível em: <www. valor.com.br/empresas/4781535/fintechs-se-organizam-para-crescer>. Acesso em: 07 abr. 2018.

PAMPLONA, N. BNDES prepara fundo de R $\$ 200$ milhões para emprestar a start-ups. Folha de São Paulo, 24 mar. 2017. Disponível em: <www1.folha.uol.com.br/mercado/2017/03/1869425-bndes-prepara-fundo-de-r-200-milhoes-para-emprestar-a-start-ups.shtml>. Acesso em: 28 jun. 2018.

PERRIN, F. Regulamentação deixa espaço para fintechs crescerem. Folha de São Paulo, 30 maio 2018. Disponível em: <www1.folha.uol.com.br/mercado/2018/05/regulamentacao-deixa-espaco-para-fintechs-crescerem.shtml> Acesso em: 28 jun. 2018.

PORTER, M. What is Strategy? Harvard Business Review, p. 61-78, nov./dez. 1996.

. The five competitive forces that shape strategy. Harvard Business Review, v. 86, n. 1, p. 57-71, jan. 2008. 
Um Olho no Peixe e Outro no Gato: Como as Fintechs Disputam Espaço com os Bancos em Época de Juros Baixos An Eye on the Fish and Another on the Cat: How the Fintechs Dispute Space with the Banks in Times of Low Interest Raul Beal Partyka | Jeferson Lana | Marina Amado Bahia Gama

PRADO, M.; CARNEIRO, M. Fintechs poderão conceder crédito sem mediação de banco. Folha de São Paulo, 26 abr. 2018. Disponível em: <www1.folha.uol.com.br/mercado/2018/04/bc-da-sinal-verde-para-fintech-conceder-credito-sem-intermediacao-de-banco.shtml> Acesso em: 27 abr. 2018.

PWC. Redrawing the lines: FinTech's growing influence on Financial Services. In: Global FinTech Report 2017. Disponível em: <www.pwc.com/gx/en/industries/financial-services/assets/pwc-global-fintech-report-2017.pdf>. Acesso em: 14 abr. 2018.

RABELLO: nova diretoria do BNDES vai reduzir intermediação para pequena empresa. Revista IstoÉ, 08 mar. 2018. Disponível em: <https://istoe.com.br/rabello-nova-diretoria-do-bndes-vai-reduzir-intermediacao-para-pequena-empresa/> Acesso em: 27 abr. 2018.

RIZÉRIO, L. Por que o Brasil simplesmente não imprime dinheiro para pagar as dívidas? Ilan Goldfajn responde. Infomoney, 27 abr. 2018. Disponível em: <www.infomoney.com.br/mercados/noticia/7395412/ por-que-brasil-simplesmente-nao-imprime-dinheiro-para-pagar-dividas $>$. Acesso em: 27 abr. 2018.

ROBERTS, R. W.; DWYER, P. D.; SWEENEY, J. T. Political strategies used by the US public accounting profession during auditor liability reform: The case of the Private Securities Litigation Reform Act of 1995. Journal of Accounting and Public Policy, v. 22, n. 5, p. 433-457, 2003. DOI: 10.1016/j.jaccpubpol.2003.08.001.

RODRIGUES, B. Com aporte de R $\$ 46$ milhões, Banco Central autoriza a fintech Toro Investimentos a criar corretora de valores. ADVFN News, 05 abr. 2018. Disponível em: <https://br.advfn.com/jornal/2018/04/ com-aporte-de-r-46-milhoes-banco-central-autoriza-a-fintech-toro-investimentos-a-criar-corretora-de-valores>. Acesso em: 07 abr. 2018.

SAMBRANA, C. David Vélez. Negócios. Isto É Dinheiro, 20 out. 2017. Disponível em: <www.istoedinheiro. com.br/david-velez/>. Acesso em: 07 abr. 2018.

SANT'ANA, T. E se o governo imprimisse mais dinheiro para dar aos pobres? Mundo Estranho. Superinteressante, 18 maio 2017. Disponível em: <https://super.abril.com.br/mundo-estranho/e-se-o-governo-imprimisse-mais-dinheiro-para-dar-aos-pobres/> Acesso em: 28 jun. 2018.

SICSÚ, J. Quem tem medo da falta de espaço fiscal? Carta Capital, 24 abr. 2017. Disponível em: <www. cartacapital.com.br/opiniao/quem-tem-medo-da-falta-de-espaco-fiscal/> Acesso em: 23 jun. 2018.

SLOBODA, L.; DUNAS, N.; LIMAŃSKI, A. Contemporary challenges and risks of retail banking development in Ukraine. Banks and Bank System, v. 13, n. 1, p. 88-97, 2018. DOI: 10.21511/bbs.13(1).2018.09. SREEHARSHA, V. Goldman Sachs sees big potential for Fintech in Brazil, The New York Times, 15 maio 2017. Disponível em: <www.nytimes.com/2017/05/15/business/dealbook/goldman-sachs-sees-big-potential-for-fintech-in-brazil.html> Acesso em 07 abr. 2018.

TRINDADE, P. Fintechs se organizam para fortalecer setor. Fecomércio-SP, 29 nov. 2017. Disponível em: <www.fecomercio.com.br/noticia/fintechs-se-organizam-para-fortalecer-setor>. Acesso em: 10 abr. 2018.

VASCONCELOS, F. C.; CYRINO, A. B. Vantagem competitiva: os modelos teóricos atuais e a convergência entre estratégia e teoria organizacional. RAE - Revista de Administração de Empresas, vol. 40, n.4, p. 20-37, out./dez. 2000. DOI: 10.1590/S0034-75902000000400003.

WONGLIMPIYARAT, J. FinTech banking industry: a systemic approach. Foresight, v. 19, n. 6, p. 590-603, 2017. DOI: 10.1108/FS-07-2017-0026. 
ZHANG, J.J.; MARQUIS, C.; QIAO, K.Y. Do political connections buffer firms from or bind firms to the government? A study of corporate charitable donations of chinese firms. Organization Science, v. 27, n. 5, p. 1307-1324, 2016. DOI: 10.1287/orsc.2016.1084.

ZOGBI, P. Nubank contrata Gustavo Franco, ex-presidente do BC. Infomoney. 27 jul 2017. Disponível em: <www.infomoney.com.br/negocios/grandes-empresas/noticia/6828275/nubank-contrata-gustavo-franco-presidente>. Acesso em: 10 abr. 2018.

. Ilan diz que BC irá atacar o spread bancário "pela raiz". Infomoney, 06 abr. 2018. Disponível em: $<$ www.infomoney.com.br/negocios/grandes-empresas/noticia/7366570/ilan-diz-que-ira-atacar-spread-bancario-pela-raiz>. Acesso em: 10 abr. 2018. 